\title{
Anti-predator behaviour in the green-lipped mussel Perna viridis: byssus thread production depends on the mussel's position in clump
}

\author{
S. G. Cheung ${ }^{1}$, F. Y. Yang ${ }^{1}$, J. M. Y. Chiu ${ }^{1}$, C. C. Liu ${ }^{1}$, P. K. S. Shin ${ }^{1,2, *}$ \\ ${ }^{1}$ Department of Biology and Chemistry, City University of Hong Kong, Kowloon, Hong Kong \\ ${ }^{2}$ Centre for Coastal Pollution and Conservation, City University of Hong Kong, Kowloon, Hong Kong
}

\begin{abstract}
Green-lipped mussels Perna viridis secrete a larger number of byssus threads to anchor themselves to the substrate more firmly when predation risks are high. These mussels also form clumps. As predators usually attack clumps from the periphery, the predation risks of solitary mussels are higher than those of mussels living along the edge of clumps, which are in turn higher than those of mussels living within the clumps. The byssus thread number, length and diameter were investigated in relation to the mussels' position in the clump. We set up chemical stimulus treatments with damaged conspecifics and heterospecifics, suggesting predation risks, as well as with intact conspecifics and heterospecifics, shrimp cues and control (no cue). The mean number of byssus threads produced was significantly affected by both the mussels' position in the clump, the treatment type, and the interactive effect between these 2 variables. In the treatment in which mussels were exposed to damaged conspecific cues, the mean number of byssus threads produced by the solitary mussels was greater than the number produced by edge mussels, which was, in turn, greater than the number produced by the mussels within the clump. Furthermore, the solitary and edge mussels exposed to damaged conspecifics secreted more byssus threads than their counterparts in the control, intact conspecifics, intact and damaged heterospecifics, and shrimp meat treatments. However, the mussels within the clumps exposed to damaged conspecifics did not secrete more byssus threads than their control counterparts. Results of the present study suggest that the anti-predator responses to risk may be related to the presence of damaged conspecifics and the mussels' position in the clump, both indicative of local predation pressure.
\end{abstract}

KEY WORDS: Anti-predator behaviour $\cdot$ Byssus $\cdot$ Clumping $\cdot$ Mussel $\cdot$ Perna viridis

\section{INTRODUCTION}

Predation is an important ecological factor that affects the behaviour, physiology, morphology and lifehistory traits of individual prey, as well as the characteristics of the prey population (Lima \& Dill 1990, Kats \& Dill 1998, Lima 1998). Prey may develop a variety of responses to increase its resistance to predation (e.g. Hagen et al. 2002, Smee \& Weissburg 2006). It is generally assumed that the costs of increased anti-predator response would, however, be translated into a reduction in reproductive output or in long-term survival (Lima 1998). It is therefore crucial for a prey organism to be able to detect predation risks and show inducible anti-predator defence when risks are variable and unpredictable (Harvell 1990). This allows the prey to reduce the chance of being injured or killed while minimizing the energy spent on anti-predator responses.

Aquatic animals use chemical signals from the environment for assessing predation risks. These chemical signals may be emitted by the predator per se, or by conspecific or heterospecific prey that is attacked, injured, or captured by a predator (Wisenden 2000). For example, when exposed to damaged conspecifics, the green sea urchin Strongylocentrotus droebachiensis and the hard clam Mercenaria mercenaria showed 'flight response' and reduced feeding, respec- 
tively (Hagen et al. 2002, Smee \& Weissburg 2006), while the crab Heterozius rotundifrons remained in a limb-extended posture in the presence of damaged heterospecifics (Hazlett \& McLay 2005). In the case of mussels, damaged conspecific cues induced Mytilus edulis to increase shell thickness and Perna viridis to secrete more byssus threads (Leonard et al. 1999, Cheung et al. 2004, Fässler \& Kaiser 2008).

Byssus threads enable mussels to anchor themselves firmly to the substratum. Enhancement of attachment strength by means of increasing the number and length of byssus threads is an inducible anti-predator response employed by mussels (e.g. Cheung et al. 2004). As tensile stress increases with length, an increase in the length of byssus threads will increase the pulling force required to break the threads (Bell \& Gosline 1997). A crab must dislodge a mussel from the anchoring substratum first before consuming it. Enhanced attachment strength can reduce the chance that the mussel will be consumed by the crab, since the time for dislodgement is increased (Lin 1991). This is especially beneficial to Perna viridis, the major predators of which are tidally migrating swimming crabs such as Thalamita danae, which have a limited foraging time (Cheung et al. 2004).

Byssus thread production is energetically costly. It accounts for 3 to $10 \%$ of the annual production in Perna viridis (Cheung 1991) and about $15 \%$ of total body energy in the ribbed mussel Aulacomya ater (Griffiths \& King 1979). In addition, $44 \%$ of the carbon budget and $21 \%$ of the nitrogen budget allocated to summer growth in Mytilus edulis were taken up by byssus thread production (Hawkins \& Bayne 1985).

Clumping can effectively reduce predation risks in mussels (Reimer \& Tedengren 1997). Mortality due to predation was reduced in beds of the ribbed mussel Geukensia demissa where clumping was extensive (Bertness \& Grosholz 1985). Mussels living in the centre of clumps are more difficult to hold and catch than individuals living at the clump edge or solitary mussels (Svane \& Ompi 1993). Predators such as crabs, predatory snails and starfish usually attack mussel clumps from the periphery; hence, mussels along the edge are more likely to be preyed upon (Okamura 1986). If the levels of predation risks faced by mussels living solitarily and along the edge and at the centre of clumps are different, the immediate needs of inducible antipredator defence for these mussels should not be the same. As byssus thread production is energetically costly, it would be advantageous for mussels to only allocate energy to produce more byssus threads when there is a higher risk of predation, i.e. when they live solitarily or along the edge of clumps.

The present study examined the byssus thread production of the green-lipped mussel Perna viridis, living solitarily and along the edge of and within clumps, when exposed to damaged and intact conspecifics and heterospecifics, shrimp cues and control (no cue). Previous studies have investigated byssus thread production of Hormomya mutabilis, Mytilus edulis and $P$. viridis that were held individually in vessels (e.g. Côte 1995, Ishida \& Iwasaki 2003, Cheung et al. 2004, 2006). No study has directly addressed how the mussels' position in clumps affects byssus thread production when exposed to cues related to predation risks. We hypothesized that mussels living solitarily produce more byssus threads than those living along the edge of clumps, which, in turn, produce more byssus threads than those living within clumps. We also hypothesized that mussels would increase byssus thread production upon exposure to damaged conspecifics and heterospecifics.

\section{MATERIALS AND METHODS}

Collection and maintenance of mussels used in experiments. Juveniles of the green mussel Perna viridis (shell length: 15 to $20 \mathrm{~mm}$ ) and the black mussel Brachidontes variabilis (shell length: 12 to $17 \mathrm{~mm}$ ), which were within the size range eaten by the swimming crab Thalamita danae (Hughes \& Seed 1995), were collected from a sheltered boulder shore at Sham Pui Chau, Tolo Harbour, Hong Kong $\left(22^{\circ} 20^{\prime} \mathrm{N}\right.$, $\left.114^{\circ} 10^{\prime} \mathrm{E}\right)$, where they co-occurred with their predator (Hughes \& Seed 1995). The B. variabilis mussels were used to generate damaged heterospecific cues and not studied for their anti-predator behaviour. Upon return to the laboratory, the mussels were cleaned of epibionts and detached carefully from their clumps by cutting the byssus threads with scissors to avoid damaging the pedal apparatus, which would impair byssus secretion (Cheung et al. 2004). Each mussel species was kept in a separate fiber-glass tank (500 l) equipped with a filtering system and an air supply. Mussels were fed the brown alga Thalassiosira pseudonana once every day. Mussels were allowed to acclimate to laboratory conditions for $1 \mathrm{wk}$ before the start of the experiment. The seawater was maintained at $28^{\circ} \mathrm{C}$ by a thermostatic heater and at a salinity of $30 \%$ during the acclimation period and throughout the experiment.

Experimental setup. A total of 6 treatments were prepared and 3 aquaria were assigned to each treatment as replicates. We randomly selected 100 Perna viridis mussels, which were assigned to each of the 3 replicate aquaria (4 l). Each aquarium was divided into 2 compartments by nylon mesh, separating the experimental mussels and the stimulus source to prevent any physical contact while allowing chemical cues to be transmitted between the compartments. An air stone 
was placed in the stimulus compartment to facilitate water mixing. The walls and bottom of the aquaria were covered with a transparent plastic sheet to provide a platform for byssus thread attachment and for the ease of byssus thread examination. The mussels were placed equidistant from each other $(5 \mathrm{~mm})$, in a square pattern, at the start of the experiment.

In the broken green mussels treatment (BG), 8 individuals of Perna viridis were crushed and placed in the stimulus compartment to generate damaged conspecific cues. The number of mussels used was predetermined from a preliminary experiment as the minimum number to induce increased secretion of byssus threads. In the second treatment of intact green mussels (IG) experiment, the same number of intact conspecifics was used. In the third treatment of broken black mussels (BB), the biomass of crushed Brachidontes variabilis used to generate damaged heterospecific cues was the same as $P$. viridis in the first 2 treatments. In the fourth treatment, broken black mussels were replaced by intact black mussels (IB) (intact heterospecifics). Shrimp tissue was used to test the effect of unfamiliar cues on byssus thread secretion in $P$. viridis in the fifth treatment, the shrimp cue (SC). No stimulus or cue was introduced in the sixth treatment, the control (C). Seawater and sources of cues were renewed for all treatments $24 \mathrm{~h}$ after the experiment started. The experiment lasted for $48 \mathrm{~h}$.

Clump formation and mussel position. The positions of all mussels were recorded with a digital camera $48 \mathrm{~h}$ after the onset of the experiment. The number of mussels forming clumps and the number of clumps in each of the replicate aquaria were recorded. The average clump size was calculated by dividing the number of mussels forming clumps over the number of clumps. Furthermore, mussels were divided into 3 different categories according to their positions: (1) solitary mussels, which did not have any physical contact with other mussels; (2) edge mussels, which were positioned at the outer boundary of a clump, i.e. without a neighbour on either the left or the right side; and (3) within-clump mussels, which were surrounded by and in contact with other mussels on all sides. A clump was defined as 2 or more mussels in physical contact or that were attached to each other by byssus threads.

Byssus thread production. The byssus threads produced by mussels were examined to evaluate the level of anti-predator response in the mussels located at different positions in the clumps after $48 \mathrm{~h}$. The numbers of byssus threads produced were counted, and their lengths and diameters were measured. The number of mussels examined depended on the number of mussels in each category (solitary, edge, or within-clump). A maximum of 10 mussels from each clump was randomly selected and examined if the number of mussels in a category exceeded 10 . However, all mussels in a category were examined if the number of mussels in that category was $<10$. The number of byssus threads produced by mussels at different positions was counted after cutting them, as close as possible to the point of insertion between the valves, with a dissection blade under a dissecting microscope. Cutting the threads where the valves closed inevitably meant that the portion within the valves was missed. It was assumed that this portion was negligible in measuring the length of byssus threads. Digital photos of the byssus threads were taken and the length of each thread was measured using the software Carnoy 2.0 at a magnification of $100 \times$. The diameter of byssus threads (at 1 to $1.5 \mathrm{~mm}$ from the adhesive disc) was directly measured to the nearest $0.0025 \mathrm{~mm}$ under a compound microscope (400x) equipped with an ocular micrometer.

Statistical analysis. Percentage data were arcsine transformed before analysis (Zar 1999). The normality of the data and homogeneity of variances were checked with Kolmogorov-Smirnov's test and Bartlett's test, respectively. The mean number of clumps formed and average clump size were square-root transformed to normalize data. The mean percentage of mussels forming clumps, the number of clumps and the average clump size were analyzed using 1-way analysis of variance (ANOVA), df $=5$ for all cases. The data for mean number, length and diameter of byssus threads produced by mussels in the same category in a replicate aquarium were pooled. These data were then analyzed using 2-way ANOVA (Position $\times$ Treatment). The fixed factors for Position were Solitary, Edge and Within-clump, and those for the treatments were BG, IG, BB, IB, SC and C. There were 3 measurements each for the different position and treatment combinations, yielding 54 total degrees of freedom (3 replicates $\times 3$ positions $\times 6$ treatments). The data were subsequently analyzed using 1-way ANOVA at fixed treatment ( $\mathrm{df}=5$ for all cases) or position levels ( $\mathrm{df}=2$ for all cases) when a significant difference was detected using 2-way ANOVA. Furthermore, Tukey's honestly significant difference pair-wise multiple comparison was used for post-hoc analysis when a significant difference was detected using 1-way ANOVA. A Bonferroni adjustment was done for the correction of Type I errors by dividing the acceptable level (0.05) by the number of comparisons being made. The new alpha values after the Bonferroni adjustment, in the case of post-hoc analysis comparing means of different positions and treatments, were 0.017 and 0.003 , respectively. The statistical tests were performed using the statistical software Sigmastat 3.0, SPSS 11.0, and Minitab 14.0. Untransformed data are presented in all figures. 


\section{RESULTS}

\section{Clump formation}

Most of the mussels Perna viridis started to explore their surroundings by extending their mobile and long feet shortly after being placed into the aquaria. Over $70 \%$ of the mussels engaged in clumping $3 \mathrm{~h}$ after the experiment started in all treatments, including the BG, IG, BB, IB, SC and C treatments. The mean percentage of mussels forming clumps at $48 \mathrm{~h}$ ranged from $90.3 \%$ in $\mathrm{BB}$ to $92.7 \%$ in IB and C treatments $(\mathrm{n}=3$ for all cases). The mean number of clumps formed in a replicate aquarium ranged from 10.7 in IG to 12.7 in IB treatments ( $\mathrm{n}=3$ for all cases). The mean average clump size ranged from 7.04 in BB to 11.5 in C treatments (an average was first calculated for each replicate and then the mean was calculated using the 3 average values; $\mathrm{n}=3$ for all cases). The mean percentage of mussels forming clumps, mean number of clumps formed and mean average clump size were not affected by the treatment $(\mathrm{p}=0.966,0.168$ and 0.123 , respectively; 1-way ANOVA).

\section{Byssus thread production}

The mean number of byssus threads produced was significantly affected by the mussels' position and the treatment, and the interactive effect between these 2 variables (Table 1). The mean number of byssus threads was significantly affected by the mussels' position in the BG treatment (Fig. 1). The mean number of byssus threads produced by the solitary mussels was 20 threads ind. ${ }^{-1}$ more than the number produced by the edge mussels, which, in turn, was 12 threads ind. ${ }^{-1}$ more than the number produced by the within-clump mussels. The difference between the solitary mussels and the mussels within clumps was statistically significant (Fig. 1). However, the mean number of byssus threads was also slightly affected by the mussels' position in the IG treatment ( $p=0.047$; 1 -way ANOVA), but the difference between the solitary, edge and within-clump mussels was not statistically significant in a Tukey's test after a Bonferroni adjustment ( $p$ > 0.017 in all comparisons). In contrast, the mean number of byssus threads was not significantly affected by the mussels' position in the $\mathrm{BB}, \mathrm{IB}, \mathrm{SC}$ and $\mathrm{C}$ treatments $(p=0.101,0.290,0.248$ and 0.086 , respectively; 1-way ANOVA).

The effects of treatment on the mean number of byssus threads were significant for the solitary and edge mussels (Fig. 2). The solitary mussels in the BG treatment secreted significantly higher numbers of byssus threads than the solitary mussels in the BB, IB,
Table 1. Perna viridis. Two-way ANOVA results showing the effects of Position (fixed factors: Solitary, Edge and Withinclump), Treatment (fixed factors: broken green mussels, intact green mussels, broken black mussels, intact black mussels, shrimp cues and control), and their interaction on the mean: number, length and diameter of byssus threads. Total df $=54$ ( 3 replicates $\times 3$ positions $\times 6$ treatments)

\begin{tabular}{|lrcrc|}
\hline Source of variation & df & MS & $F$ & $p$ \\
\hline Number of byssus threads & & & & \\
Position & 2 & 0.141 & 10.05 & $<0.001$ \\
Treatment & 5 & 0.278 & 19.81 & $<0.001$ \\
Position $\times$ Treatment & 10 & 0.061 & 4.32 & 0.001 \\
Error & 36 & 0.014 & & \\
Length & & & & \\
Position & 2 & 0.466 & 0.448 & 0.642 \\
Treatment & 5 & 1.835 & 1.764 & 0.145 \\
Position $\times$ Treatment & 10 & 0.597 & 0.574 & 0.824 \\
Error & 36 & 1.040 & & \\
Diameter & & & & \\
Position & 2 & $1.44 \times 10^{-6}$ & 0.102 & 0.903 \\
Treatment & 5 & $1.07 \times 10^{-5}$ & 0.755 & 0.588 \\
Position $\times$ Treatment & 10 & $9.40 \times 10^{-6}$ & 0.666 & 0.748 \\
Error & 36 & & & \\
\hline
\end{tabular}

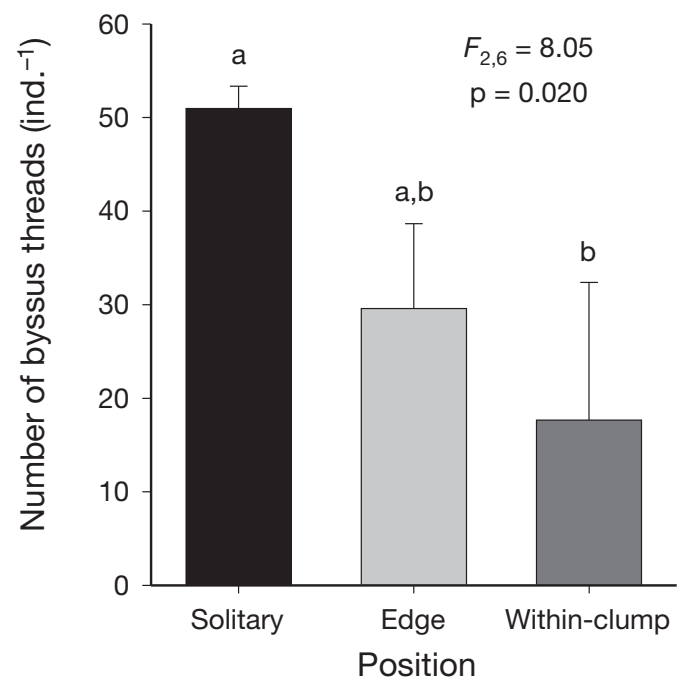

Fig. 1. Perna viridis. Effects of mussel position (solitary, edge and within-clump) on the number (mean $+\mathrm{SD}$ ) of byssus threads produced by mussels in the broken green mussel (BG) treatment. 1-way ANOVA results are shown. Means that are significantly different are indicated by different letters above the bars (Tukey's test, $\mathrm{p}<0.017$ after Bonferroni adjustment)

SC and C treatments. Similarly, the mean number of byssus threads secreted by the edge mussels in the BG treatment was significantly higher than those in the $\mathrm{BB}, \mathrm{IB}, \mathrm{SC}$ and $\mathrm{C}$ treatments. However, the treatment effects on the mean number of byssus threads were not significant for the within-clump mussels $(p=0.478$; 1-way ANOVA). 

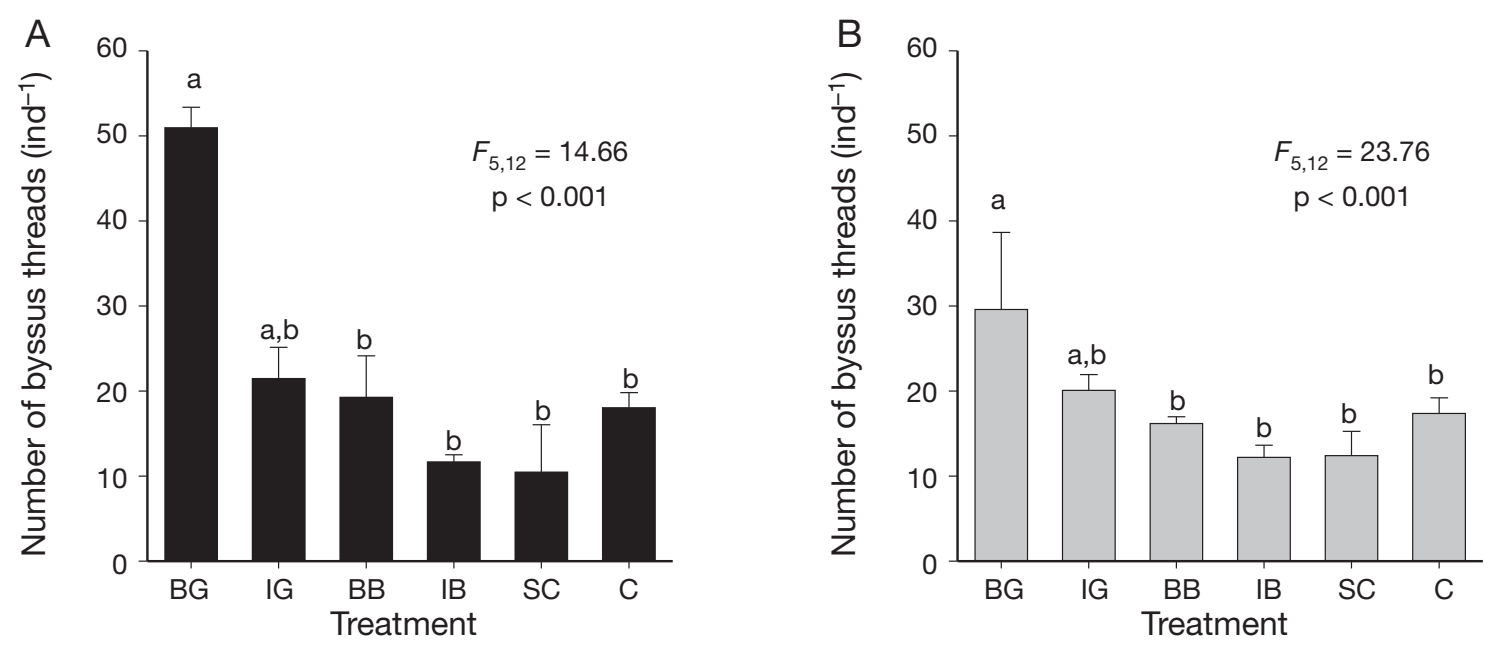

Fig. 2. Perna viridis. Effects of treatment (BG: broken green mussels; IG: intact green mussels; BB: broken black mussels; IB: intact black mussels; SC: shrimp cues; C: control) on the number (mean +SD) of byssus threads produced by (A) solitary and (B) edge mussels. 1-way ANOVA results are shown. Means that are significantly different are indicated by different letters above the bars

(Tukey's test, $\mathrm{p}<0.003$ after Bonferroni adjustment)

The mean length of byssus threads was not affected by either the mussels' position or the treatment (Table 1). The mean length ranged from $6.19 \mathrm{~mm}$ for the solitary mussels in the IG treatment to $8.26 \mathrm{~mm}$ in the edge mussels in the SC treatment. Similarly, the mean diameter of byssus threads was neither affected by the mussels' position nor the treatment (Table 1). The mean diameter of the threads ranged from $0.0297 \mathrm{~mm}$ for the within-clump mussels in the BG treatment to $0.0351 \mathrm{~mm}$ in the solitary mussels in the $\mathrm{C}$ treatment.

\section{DISCUSSION}

Results showed that the likelihood of clumping in Perna viridis was not enhanced by the presence of damaged conspecifics or, in fact, by any of the chemical stimulus treatments. This is in contrast to a previous study which found that a higher percentage of $P$. perna and Mytilus galloprovincialis mussels formed clumps in the presence of damaged conspecifics (Nicastro et al. 2007). In addition, $M$. edulis and $P$. perna mussels were more likely to form clumps in the presence of their respective predators, lobsters and starfish (Reimer \& Tedengren 1997, Côte \& Jelnikar 1999, Nicastro et al. 2007). The discrepancy between the present and previous studies could be explained by the difference in the amount of stimulus used. Nicastro et al. (2007) used a higher biomass of damaged conspecifics over the same volume of seawater than was used in the present study. Another explanation for the discrepancy could be the initial distances separating the mussels. It was shown that significantly more mussels clumped when the initial distance between individuals could be covered by the mussels' extended foot, so that only little movement and small energy expenditure were involved when mussels clumped together (Nicastro et al. 2007). Over $80 \%$ of mussels formed clumps in the predator treatment when they were initially separated by a distance equivalent to 0.5 shell lengths; whereas only about $20 \%$ of the mussels formed clumps when they were initially separated by 1.5 shell lengths. A similar study demonstrated that the percentage of mussels forming clumps was reduced from about 65 to $34 \%$ when the initial distance increased from 0.5 to 1.5 mussel shell lengths (Côte \& Jelnikar 1999). In the present study, $P$. viridis were initially separated by about 0.3 mussel shell lengths. Such a short distance between the mussels might enhance clumping. Over $70 \%$ of the mussels engaged in clumping within $3 \mathrm{~h}$ after the start of the experiment. Therefore, in the present study, the effects of damaged conspecifics on the percentage of mussels forming clumps might be affected by the short initial distance between mussels. However, the initial distance between the mussels was not varied. Verification of this argument for $P$. viridis awaits future experiments.

As predators usually attack mussel clumps from the outside, a larger clump would expose fewer mussels to the outside, hence reducing the risk of predation. However, this study showed that the mean average clump size was not affected by the presence of damaged conspecifics; as for Mytilus edulis, that clump did not grow bigger under higher predation risk (Côte \& Jelnikar 1999). There should be an optimal clump size balancing benefits and costs (Jackson 1977). A large clump offers physical stabilization to mussels, preventing them from 
being dislodged by wave action (Harger 1970). The risk of desiccation of intertidal mussels can also be alleviated as the close arrangement of individuals can help trap moisture and reduce water loss during low tides (Huang et al. 2007). However, costs are also incurred by mussels forming large clumps, as they face intense intra-specific competition (Fréchette et al. 1992, Stiven \& Gardner 1992). Mussel growth and reproductive output were negatively correlated with clump size in $M$. edulis (Okamura 1986, Svane \& Ompi 1993).

The present study investigated byssus thread number, length and diameter in correlation with position in the clump for Perna viridis. It was worthwhile to note that, although great care was taken in arranging the air stones so that water mixing in all replicate aquaria was comparable, minute differences in the resulting water motion might still have affected byssus thread production (e.g. Zardi et al. 2006, Carrington et al. 2008). Nevertheless, results showed that the mussels' position significantly affected the byssus thread number under some conditions. The solitary mussels and mussels living along the edge of clumps produced more byssus threads than the mussels living within clumps when exposed to damaged conspecifics (Fig. 1). These byssus threads also tended to be thicker and longer, but the differences were statistically insignificant. Enhanced attachment strength by means of increasing the number of byssus threads could reduce the chance of being dislodged and consumed by predators (Lin 1991). These results suggested that the anti-predator trait was accordingly heightened for the solitary and edge mussels (Fig. 1), which faced elevated predation pressure compared to the mussels within the clumps (Svane \& Ompi 1993).

This investigation further revealed that, when exposed to damaged conspecifics, the solitary and edge mussels secreted more byssus threads than their respective counterparts in the control treatment (Fig. 2). In agreement with the results here, Cheung et al. (2004) showed that byssus thread production is a plastic response in Perna viridis that can be induced by chemical signals generated by damaged conspecifics. It is believed that the ability to recognize conspecific cues is innate. The recognition of conspecific alarm cues as risk indicators generally occurs at a very early stage of development and requires no previous experience (Magurran 1989).

Our results also showed that the damaged heterospecifics of the black mussel Brachidontes variabilis did not induce byssus thread production of Perna viridis. Nevertheless, cross-species responses may occur in phylogenetically close species or in distantly related species if prey species are members of the same prey guild that share a habitat and are exposed to the same predators (Chivers et al. 1995). While damaged B. vari- abilis did not induce byssus thread production of $P$. viridis, damaged $P$. viridis did induce byssus thread production in B. variabilis (Shin et al. 2008). B. variabilis also preferred a smaller refuge when exposed to damaged P. viridis (Shin et al. 2008). Furthermore, unlike $P$. viridis, $B$. variabilis reacted to novel cues composed of shrimp meat (Shin et al. 2008). Cues released from shrimp meat might serve as a warning signal to induce byssus thread production, but the signal was greatly enhanced in the presence of cues that were more relevant to the perceived risk, i.e. cues from damaged conspecifics in the case of $B$. variabilis (Shin et al. 2008). Shin et al. (2008) also demonstrated that some common cues that are shared by different organisms might be released from injured or dead individuals and can be involved in the induction of anti-predator responses. Whether damaged heterospecifics and novel cues elicit anti-predator responses or not seems to be species-specific.

The most interesting finding in the present study is that there was a reduction in byssus thread number in the case of within-clump mussels when exposed to damaged conspecifics (Fig. 1). The within-clump mussels are embedded by other mussels, making it very difficult for their crab predators to catch and handle them (Svane \& Ompi 1993). Operating off the same principle, mussels are less vulnerable to crab predation when they are buried (Lin 1991) or live in crevices and other structural refuges (Suchanek 1978). Furthermore, since byssus thread production is energetically costly, selective force would act on the mussels within clumps to shunt energy allocated to produce byssus threads to defend against predators when the risks of predation are alleviated by the solitary and edge mussels. It was further found that the within-clump mussels did not initiate anti-predator behaviour. On the other hand, the solitary and edge mussels, which were more vulnerable to predators, reacted strongly when exposed to the damaged conspecific cues indicative of risk. Smee \& Weissburg (2008) found that the hard clam Mercenaria mercenaria living in local habitats with elevated predation pressure were be more likely to initiate predator avoidance behaviour than clams living at lower latitudes where predation pressure is less intense. Results of the present study, along with that of Smee \& Weissburg (2008), suggest that the antipredator responses to risk may be related to local predation pressure in marine bivalves.

Acknowledgements. This manuscript benefited greatly from the comments and suggestions of 3 anonymous reviewers. The work described was fully supported by a grant from the Research Grants Council of the Hong Kong Special Administrative Region to S.G.C. and P.K.S.S (Project No. CityU 1451/05M), and partially fulfils the requirements of F.Y.Y.'s MPhil degree. 


\section{LITERATURE CITED}

Bell MC, Gosline JM (1997) Strategies for life in flow: tenacity, morphometry, and probability of dislodgement of two Mytilus species. Mar Ecol Prog Ser 159:197-208

Bertness MD, Grosholz E (1985) Population dynamics of the ribbed mussel, Geukensia demissa: the costs and benefits of an aggregated distribution. Oecologia 67:192-204

Carrington E, Moeser GM, Thompson SB, Coutts LC, Craig CA (2008) Mussel attachment on rocky shores: the effect of flow on byssus production. Integr Comp Biol 48:801-807

Cheung SG (1991) Energetics of transplanted populations of the green-lipped mussel Perna viridis (Linnaeus) (Bivalvia: Mytilacea) in Hong Kong. II. Integrated energy budget. Asian Mar Biol 8:133-147

> Cheung SG, Tong PY, Yip KM, Shin PKS (2004) Chemical cues from predators and damaged conspecifics affect byssus production in the green-lipped mussel Perna viridis. Mar Freshwat Behav Physiol 37:127-135

Cheung SG, Luk KC, Shin PKS (2006) Predator-labeling effect on byssus production in marine mussels Perna viridis (L.) and Brachidontes variabilis (Krauss). J Chem Ecol 32:1501-1512

Chivers DP, Wisenden BD, Smith RJF (1995) The role of experience in the response of fathead minnows (Pimephales promelas) to skin extract of Iowa darters (Etheostoma exile). Behaviour 132:665-674

Côte IM (1995) Effects of predatory crab effluents on byssus production in mussels. J Exp Mar Biol Ecol 188:233-241

Côte IM, Jelnikar E (1999) Predator-induced clumping behaviour in mussels (Mytilus edulis Linnaeus). J Exp Mar Biol Ecol 235:201-211

Fässler SMM, Kaiser MJ (2008) Phylogenetically mediated anti-predator responses in bivalve molluscs. Mar Ecol Prog Ser 363:217-225

Fréchette M, Aitken AE, Pagé L (1992) Interdependence of food and space limitation of a benthic suspension feeder: consequences for self-thinning relationships. Mar Ecol Prog Ser 83:55-62

Griffiths CL, King JA (1979) Energy expended on growth and gonad output in the ribbed mussel Aulacomya ater. Mar Biol 53:217-222

Hagen N, Andersen Å, Stabell OB (2002) Alarm responses of the green sea urchin, Strongylocentrotus droebachiensis, induced by chemically labelled durophagous predators and simulated acts of predation. Mar Biol 140:365-374

Harger JRE (1970) Comparisons among growth characteristics of two species of sea mussel, Mytilus edulis and Mytilus californianus. Veliger 13:44-56

> Harvell CD (1990) The ecology and evolution of inducible defences. Q Rev Biol 65:323-340

> Hawkins AJS, Bayne BL (1985) Seasonal variation in the relative utilization of carbon and nitrogen by the mussel Mytilus edulis: budgets, conversion efficiencies and maintenance requirements. Mar Ecol Prog Ser 25:181-188

Hazlett BA, McLay C (2005) Responses of the crab Heterozius rotundifrons to heterospecific chemical alarm cues: phylogeny vs. ecological overlap. J Chem Ecol 31:671-677

Huang D, Todd PA, Guest JR (2007) Movement and aggregation in the fluted giant clam (Tridacna squamosa L.). J Exp Mar Biol Ecol 342:269-281

Hughes RN, Seed R (1995) Behavioural mechanisms of prey selection in crabs. J Exp Mar Biol Ecol 193:225-238

Ishida S, Iwasaki K (2003) Reduced byssal thread production and movement by the intertidal mussel Hormomya muta- bilis in response to effluent from predators. J Ethol 21: $117-122$

Jackson JBC (1977) Competition on marine hard substrata: the adaptive significance of solitary and colonial strategies. Am Nat 111:743-767

Kats LB, Dill LM (1998) The scent of death: chemosensory assessment of predation risk by prey animals. Ecoscience 5:361-394

Leonard GH, Bertness MD, Yund PO (1999) Crab predation, waterborne cues, and inducible defences in the blue mussel, Mytilus edulis. Ecology 80:1-14

Lima SL (1998) Non-lethal effects in the ecology of predatorprey interactions. Bioscience 48:25-34

Lima SL, Dill LM (1990) Behavioural decisions made under the risk of predation: a review and prospectus. Can J Zool 68:619-640

Lin J (1991) Predator-prey interactions between blue crabs and ribbed mussels living in clumps. Estuar Coast Shelf Sci 32:61-69

Magurran AE (1989) Acquired recognition of predator odour in the European minnow (Phoxinus phoxinus). Ethology 82:216-223

> Nicastro KR, Zardi GI, McQuaid CD (2007) Behavioural response of invasive Mytilus galloprovincialis and indigenous Perna perna mussels exposed to risk of predation. Mar Ecol Prog Ser 336:169-175

> Okamura B (1986) Group living and the effects of spatial position in aggregations of Mytilus edulis. Oecologia 69: 341-347

Reimer O, Tedengren M (1997) Predator-induced changes in byssal attachment, aggregation and migration in the blue mussel, Mytilus edulis. Mar Freshwat Behav Physiol 30: 251-266

Shin PKS, Liu CC, Liu ZX, Cheung SG (2008) Marine mussels Brachidontes variabilis selected smaller places of refuge and enhanced byssus production upon exposure to conspecifics and heterospecifics cues. J Exp Mar Biol Ecol 361: $16-20$

> Smee DL, Weissburg MJ (2006) Hard clams (Mercenaria mercenaria) evaluate predation risk using chemical signals from predators and injured conspecifics. J Chem Ecol 32: 605-619

Smee DL, Weissburg MJ (2008) Heightened prey responses in risky habitats: predator pressure increases prey sensitivity to predator risk. Mar Ecol Prog Ser 363:39-50

- Stiven AE, Gardner SA (1992) Population processes in the ribbed mussel Geukensia demissa (Dillwyn) in a North Carolina salt marsh tidal gradient: spatial pattern, predation, growth and mortality. J Exp Mar Biol Ecol 160:81-102

Suchanek TH (1978) The ecology of Mytilus edulis L. in exposed rocky intertidal communities. J Exp Mar Biol Ecol 31: 105-120

Svane I, Ompi M (1993) Patch dynamics in the beds of the blue mussel Mytilus edulis: effect of site, patch size and position within a patch. Ophelia 37:187-202

Wisenden BD (2000) Olfactory assessment of predation risk in the aquatic environment. Philos Trans R Soc Lond 355: 1205-1208

Zar JH (1999) Biostatistical analysis, 4th edn. Prentice Hall, Englewood Cliffs; NJ

> Zardi GI, Nicastro KR, McQuaid CD, Rius M, Porri F (2006) Hydrodynamic stress and habitat partitioning between indigenous (Perna perna) and invasive (Mytilus galloprovincialis) mussels: constraints of an evolutionary strategy. Mar Biol 150:79-88 